
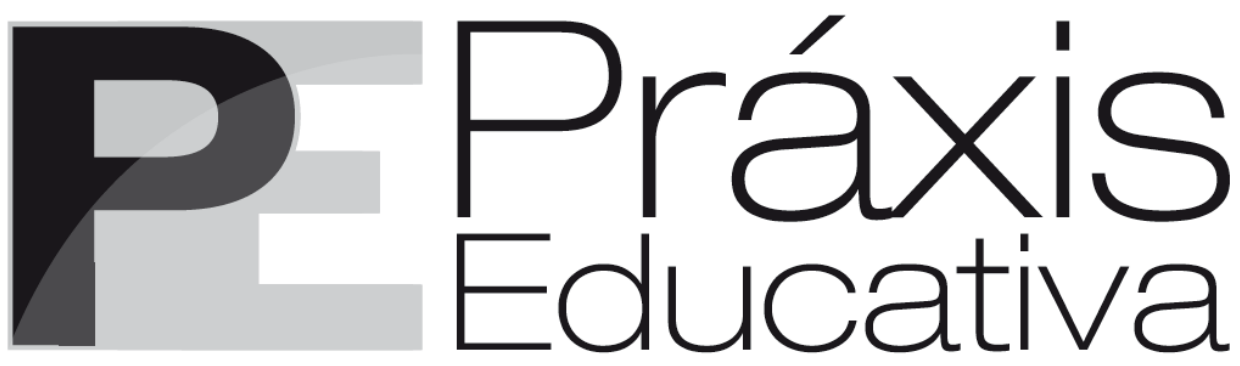

ISSN 1809-4309 (Versão online) DOI: 10.5212/PraxEduc.v.11i3.0010

\title{
Conhecimento histórico escolar: fixações de sentidos a partir de uma política de avaliação no Rio de Janeiro
}

\section{School historical knowledge: fixation of meanings from an evaluation policy in Rio de Janeiro}

\section{Conocimiento histórico escolar: fijaciones de sentidos a partir de una política de evaluación en Río de Janeiro}

\author{
Marcus Leonardo Bomfim Martins* \\ Carmen Teresa Gabriel ${ }^{* *}$
}

\begin{abstract}
Resumo: O objetivo deste artigo é problematizar as disputas por fixação de sentidos de conhecimento histórico escolar no Saerjinho - instrumento avaliativo que compõe o sistema de avaliação da rede fluminense. Concebendo o currículo como prática de significação e atribuição de sentidos e avaliação como política e prática curricular, foram analisadas informações veiculadas no site da Secretaria de Educação, questões da prova de História e entrevistas semiestruturadas com professores dessa disciplina, a partir de uma postura epistêmica discursiva na pauta pós-fundacional que entende a produção de significados como um ato político. As análises apontaram que há disputas não pelo que do conhecimento histórico fixado, mas pelo quem tem o direito de fixar tal conhecimento em um instrumento avaliativo.
\end{abstract}

Palavras-chave: Currículo. Avaliação. Conhecimento histórico escolar.

Abstract: The purpose of this paper is to problematize the dispute over the fixation of meanings of school historical knowledge in Saerjinho - the evaluative instrument that makes up the evaluation system of the network in Rio de Janeiro. Conceiving the curriculum as signification practice and attribution of meaning and evaluation as a policy and curricular practice, information provided by the website of the Department of Education was analyzed, as were questions of History exams and semi-structured interviews with teachers of this discipline, from a discursive epistemic posture in the post-foundational agenda that understands the production of meaning as a political act. The analysis showed that there are disputes not over what the set historical knowledge consists of, but over who has the right to establish such knowledge within the evaluative instrument.

Keywords: Curriculum. Evaluation. School historical knowledge.

Resumen: El objetivo de este artículo es problematizar las disputas por la fijación de sentidos de conocimiento histórico escolar en Saerjinho,-instrumento calificador que compone el sistema de evaluación de la red fluminense (del estado de Río de Janeiro). Dentro de la concepción del currículo como práctica de significación y atribución de sentidos, y de la evaluación como política y práctica

\footnotetext{
* Doutorando em Educação (PPGE/UFRJ). E-mail: <marcus.bomfim@gmail.com>.

** Professora da Universidade Federal do Rio de Janeiro (UFRJ). E-mail: < carmenteresagabriel@gmail.com>.
} 
curricular, se analizaron informaciones divulgadas en el sitio web de la Secretaría de Educación, preguntas de la prueba de Historia y entrevistas semiestructuradas con profesores de esta materia, desde el punto de vista de una postura epistémica discursiva en la pauta post-fundacional que entiende la producción de significados como un acto político. Los análisis indicaron que hay disputas no sobre el qué del conocimiento histórico fijado, sino por el quién tiene el derecho a fijar tal conocimiento en un instrumento calificador.

Palabras clave: Currículum. Evaluación. Conocimiento Histórico Escolar.

\section{Introdução}

Desde os anos de 1990 e com uma nítida intensificação nos anos 2000, o Brasil assiste a uma proliferação de políticas educacionais nas quais a avaliação assume condição de protagonista (SOUSA; OLIVEIRA, 2010), sendo concebida como elemento capaz de produzir uma educação de qualidade. As políticas de avaliação não ficaram restritas à gestão nacional da educação brasileira, mas difundiram-se também nos sistemas estaduais e municipais, independentemente da orientação político-partidária vigente nessas escalas de organização político-administrativa do Estado, o que levou Afonso (2007) a alcunhar essa proliferação de políticas educacionais com base em sistemas de avaliação de "obsessão avaliativa".

Pensando a partir do campo educacional e mais particularmente do campo do Currículo, não há relação de ensino-aprendizagem que não seja atravessada pela avaliação. Esta é uma prática curricular legitimada socialmente e enraizada nas escolas que produz efeitos para todos os sujeitos posicionados nesses espaços. De acordo com Fernandes (2009, p. 21), “[...] governos, políticos, escolas, gestores escolares, professores, pais e alunos estão todos interessados na avaliação, precisam dela ou utilizam-na, mais ou menos sistematicamente, de diversas formas". Se na escola "[...] enquanto prática curricular é a avaliação que sinaliza aos alunos o que o professor e a escola valorizam" (MARTINS, 2010, p. 7), para o poder público a avaliação vem assumindo um protagonismo como "[...] dispositivo de regulação dos sistemas de ensino" (AFONSO, 2007, p. 12).

Este artigo situa-se no contexto das discussões sobre a relação entre currículo e avaliação, definindo como objeto particular de análise o Saerjinho - avaliação oficial bimestral da Secretaria de Estado de Educação do Rio de Janeiro (SEEDUC/RJ), que faz parte do Sistema de Avaliação do Estado do Rio de Janeiro (SAERJ). Importa sublinhar que esse instrumento avaliativo foi criado pela SEEDUC/RJ em $2011 \mathrm{em}$ um contexto de crise na educação do Rio de Janeiro após a divulgação do ranking do Índice de Desenvolvimento da Educação Básica (IDEB) que colocava o estado na penúltima posição dentre todos os entes federados da União.

Consideramos que o presente texto possa contribuir para o debate em torno das políticas de avaliação ao propor o campo do Currículo como lugar de enunciação, pois defendemos a potência política desse campo para orientar discussões que tenham o conhecimento escolar como pedra angular de projetos educacionais (no caso aqui específico, o conbecimento histórico escolar). Nossa concepção de currículo como produção de significados no/para o espaço escolar é, pois, a forma escolhida para politizar o debate sobre políticas de avaliação.

Assim, o objetivo principal aqui é analisar as articulações discursivas, hegemonizadas na política de avaliação aqui privilegiada, em torno do significante conbecimento histórico escolar das quais participam docentes da disciplina História e gestores da rede estadual da educação do Rio de Janeiro. O corpo empírico da análise constitui-se de textos de diferentes naturezas como: 
entrevistas semiestruturadas com docentes de História ${ }^{1}$, provas do Saerjinho dessa disciplina aplicadas em 2013 e 2014, documentos oficiais produzidos pela SEEDUC/RJ e o site oficial da Secretaria.

Sublinhamos que as entrevistas não foram vislumbradas como codificações prévias da realidade, mas consideradas como "práticas discursivas" que pretendem oferecer mais um fechamento possível de sentidos produzidos na contingência, ressaltando que os significados instituídos pelos docentes não são neutros, fazendo, pois, parte das lutas hegemônicas que envolvem as práticas de significação das práticas e políticas curriculares.

Organizamos a discussão em quatro partes. $\mathrm{Na}$ primeira, apresentaremos as lentes teóricas escolhidas para analisar o objeto construído. $\mathrm{Na}$ segunda, explicitaremos brevemente a noção de currículo com a qual iremos operar. Em seguida, apresentaremos o Saerjinho e seu desenho, situando-o nas discussões em torno das relações entre políticas de avaliação e currículo. $\mathrm{Na}$ última seção, antes das considerações finais, traremos construtos empíricos que exprimem as disputas pela significação do conhecimento histórico escolar fixado na política de avaliação educacional do Rio de Janeiro.

\section{Ajustando as lentes e afiando os instrumentos}

A problematização aqui proposta encontra-se assente em uma visão de mundo que nega a existência de essências totalizantes e metafísicas produzidas fora do jogo da linguagem. Dessa forma, o presente estudo orienta-se por uma perspectiva discursiva na pauta pós-fundacional, a partir da qual se entende que a linguagem não nomeia o que existe no mundo, mas institui aquilo que está nomeando. Nessa abordagem, não existe realidade material que não seja acessada via produção de discurso, isto é, pela produção de significados a partir de práticas articulatórias.

Assim, dentre a pluralidade de abordagens discursivas disponíveis, optamos pela Teoria do Discurso, de Ernesto Laclau e Chantal Mouffe, que se inscreve na pauta pós-fundacional e toma o discurso como uma categoria analítica na qual as articulações políticas, atravessadas por relações assimétricas de poder, desempenham um papel constitutivo na construção/leitura do social.

Operar, no entanto, teórica e metodologicamente a partir da abordagem pós-fundacional não significa negar a ausência de fundamentos, mas implica em "[...] abrirmos mão de certezas e verdades apoiadas em fundamentos metafísicos que se situam fora do jogo da linguagem" (GABRIEL, 2013b, p. 57). Nesse sentido, Marchart (2009) explica com clareza esta postura epistêmica:

O enfraquecimento ontológico do fundamento não conduz à suposição da ausência total de todos os fundamentos, mas sim supõe a impossibilidade de um fundamento último, o que é algo inteiramente diferente, porque implica na crescente consciência, por um lado, da contingência e, por outro lado, do político como momento de uma fundação parcial e, definitivamente, sempre incompleta. (MARCHART, 2009, p. 15, tradução livre).

$\mathrm{Na}$ abordagem pós-fundacional, a realidade social aparece como algo a ser compreendido a partir da sua infinidade de formas, das várias possibilidades de alcançar-se múltiplas verdades, contingentes e precárias. Partimos, portanto, do pressuposto teórico de que toda totalidade é

\footnotetext{
${ }^{1}$ Entrevistas realizadas com docentes de História que lecionam em escolas cujos resultados obtidos pelos alunos na parte dessa disciplina escolar que compõe a avaliação aqui em destaque têm o mesmo padrão de acertos, e fazem parte da mesma coordenadoria administrativa da SEEDUC/RJ.
}

Práxis Educativa, Ponta Grossa, p. 693-713, v. 11, n. 3, set./dez. 2016 Disponível em: <http://www.revistas2.uepg.br/index.php/praxiseducativa> 
inalcançável de forma imediata e definitiva, havendo apenas fechamentos provisórios e contingentes de sentidos que permitem construir o social. Essa abordagem desconfia das afirmações categóricas e genéricas, dando preferência às interpretações parciais e localizadas. Como afirma Marchart (2009), esse quadro de inteligibilidade permite uma "[...] dissolução dos marcadores de certeza específicos como fundamento do social [...]" (MARCHART, 2009, p. 19), o que vai ao encontro da afirmação de Laclau de que "[...] toda configuração social é uma configuração significativa" (LACLAU, 2005, p. 114).

No processo de significação são mobilizadas duas lógicas, a "lógica de equivalência" e a "lógica de diferença". Ambas as lógicas são interligadas, não podendo ser pensadas isoladamente. Howarth (2000) clarifica bem a forma como Laclau e Mouffe significam a lógica da equivalência no processo de construção de uma formação discursiva:

\footnotetext{
[a lógica da equivalência] consiste na dissolução das identidades particulares de sujeitos dentro de um discurso pela criação de uma identidade puramente negativa que é vista como uma ameaça a eles. Em outras palavras, na lógica de equivalência, se os termos $a$, $b$ e $c$ são tornados equivalentes $(a \equiv b \equiv c)$ em relação à característica $d$, então $d$ deve negar totalmente $a, b$ e $c(d=-(a, b, c)$, assim subvertendo os termos originais do sistema. Isso significa que a identidade daqueles interpelados por um discurso seria sempre dividida entre um grupo particular de diferenças conferidas por um sistema discursivo existente $(a, b, c)$ e a ameaça mais universal colocada pelo exterior discursivo (d). (HOWART, 2000, p. 106-107, tradução nossa).
}

Nas palavras do próprio Laclau (2005, p. 94, tradução nossa), “[...] todas as outras diferenças são equivalentes entre si, equivalentes em sua rejeição comum à identidade excluída”. Ou seja, o que é politicamente expelido da cadeia de equivalências é o inimigo que passa a ser comum de todos os elementos que, naquela formação discursiva, enfraquecem-se como unidades diferenciais podendo manter-se equivalentes em relação a outro diferente que, do exterior, permite a produção e o fechamento contingencial e provisório dessa cadeia. $\mathrm{Na}$ teoria laclauniana, esse inimigo comum é chamado de exterior constitutivo, e é ele que, ao ser colocado para fora da cadeia equivalencial, confere identidade aos que estão do lado de dentro.

Nessa abordagem discursiva, a produção de significados é sempre a produção de um sentido particular que se hegemoniza quando se torna capaz, por meio de diferentes dispositivos, de aglutinar outros sentidos e ser alçado à condição de universal. De acordo com Burity (2008), é a "[...] capacidade de representar, enquanto uma posição particular, algo maior, mais abrangente, que Laclau dá o nome de hegemonia" (BURITY, 2008, p. 44). "Trata-se de um processo de universalização do particular.” (BURITY, 2008, p. 48).

Em Emancipação e Diferença (2011), Ernest Laclau define, de forma mais simples, hegemonia como "luta de poder" (LACLAU, 2011, p. 50). São, portanto, as lutas de poder entre professores de História e o governo fluminense, em torno dos sentidos de conhecimento histórico escolar que iremos explorar neste texto.

É a partir dessa perspectiva armada que, neste texto, enfrentaremos as questões apresentadas na introdução como objeto de investigação.

\section{Currículo na perspectiva discursiva pós-fundacional}

Descartamos de imediato a ideia de que há um significado único e engessado para pensarmos o currículo, decorrendo daí a necessidade de esclarecer o entendimento de currículo com o qual operaremos ao longo deste artigo. Não há, a partir dos referenciais nos quais sustentamos esta pesquisa, uma essência que defina currículo. Na visão de Lopes e Macedo

Práxis Educativa, Ponta Grossa, p. 693-713, v. 11, n. 3, set./dez. 2016 Disponível em: <http://www.revistas2.uepg.br/index.php/praxiseducativa> 
(2011, p. 19), há apenas “[...] acordos sobre sentidos de tal termo, sempre parciais e localizados historicamente".

Perspectivas presentes nos debates curriculares contemporâneos defendem a pertinência de operar-se com as noções de currículo que o compreende como "prática de significação", "espaço de fronteira", "entre-lugar" e "espaço de enunciação". Em sintonia com a abordagem discursiva pós-fundacional que orienta a postura epistêmica no qual este artigo se inscreve, defendemos que o currículo é capaz de oferecer

[...] uma forma de nomear e narrar o real em nosso tempo que simultaneamente se assume descrevendo-o e intervindo sobre ele, reconfigurando-o ou buscando fazê-lo, frente a outras formas de representar o real. De modo que há, sim, uma disputa pelo que há, pelo que está acontecendo, pelo para-onde-vão as coisas, em suma, mais do que uma guerra de interpretações, uma disputa hegemônica pelo mundo em que vivemos. (BURITY, 2010, p. 8).

Do mesmo modo, concordamos com Frazão (2014, p. 14) quando afirma que "[...] não existiria um objeto lá fora que podemos chamar de currículo: este é construído e negociado nas relações de poder existentes nas diferentes esferas do processo educativo". Na mesma linha, Lopes e Macedo (2011) explicitam bem como é conceber o currículo na perspectiva teórica aqui assumida:

\footnotetext{
O currículo é, ele mesmo, uma prática discursiva. Isso significa que ele é uma prática de poder, mas também uma prática de significação, de atribuição de sentidos. Ele constrói a realidade, nos governa, constrange nosso comportamento, projeta nossa identidade, tudo isso produzindo sentidos. Trata-se, portanto, de um discurso produzido na interseção entre diferentes discursos sociais e culturais que, ao mesmo tempo, reitera sentidos opostos por tais discursos e os recria. Claro que, como essa recriação está envolta em relações de poder, na interseção em que ela se torna possível, nem tudo pode ser dito. (LOPES; MACEDO, 2011, p. 41).
}

Nessa perspectiva, apropriamo-nos da definição de currículo como "espaço-tempo de fronteira cultural" (MACEDO, 2006) e como prática de significação e atribuição de sentidos entre outros, de conhecimento escolar, contingencialmente fixados (GABRIEL, 2013a, 2013b).

Esse entendimento de currículo possibilita compreender o Saerjinho como uma política e uma prática curricular que se constitui como espaço discursivo no qual são hegemonizados, por meio de práticas articulatórias construídas no jogo político, diversos sentidos, dentre os quais aquele que elegemos como objeto a ser explorado neste texto: as disputas pela fixação dos sentidos de conhecimento histórico validado como legítimo a ser ensinado e avaliado na Educação Básica da rede pública do Rio de Janeiro. Além da percepção dessa avaliação como espaço de hegemonização, ela também pode ser vista como espaço no qual a própria luta pelo direito de dizer faz-se presente.

Assim, o Saerjinho é não somente um lócus de produção de significados, mas também um ato de significação, pois, ao mesmo tempo que são produzidas cadeias equivalenciais para definila como "boa", "necessária”, “justa", "legítima”; ou "ruim”, "dispensável”, “injusta”, "sem legitimidade"; a avaliação passa a significar também o que seria "educação de qualidade", "conhecimento válido", "bom aluno", "mau aluno", "bom professor", "mau professor", "bom gestor", "mau gestor", "boa escola", "má escola”, "bom ensino”, "mau ensino”, dentre outras possibilidades de adjetivação de processos e sujeitos.

Práxis Educativa, Ponta Grossa, p. 693-713, v. 11, n. 3, set./dez. 2016 Disponível em: <http://www.revistas2.uepg.br/index.php/praxiseducativa > 


\section{Políticas de avaliação: o que o currículo tem a ver com isso?}

O protagonismo da avaliação nas políticas educacionais contemporâneas gera intensos debates entre aqueles que, dentre outros aspectos, enfatizam os efeitos danosos das políticas de avaliação sobre as práticas curriculares e relações sociais circunscritas no espaço escolar, e grupos que defendem essas políticas como caminho para a reestruturação da gestão dos sistemas de ensino com base em aspectos consolidados do mundo empresarial: eficiência, eficácia e qualidade.

O presente texto tenta compreender como os sentidos que cada lado produz em torno da questão da avaliação são discursivamente elaborados, fazendo, pois, uma aposta política na produção de híbridos potentes para a democratização da produção, distribuição e consumo do principal bem simbólico que a escola pode oferecer: o conhecimento (GABRIEL; CASTRO, 2013).

Pensando na questão da emergência e da expansão das políticas educacionais centradas na avaliação, como mencionado anteriormente, Afonso (2007) cria o conceito de "obsessão avaliativa" para dar conta de "[...] um estatuto relativamente indiferente às concepções políticoideológicas", assim como "[...] uma certa imunidade ou indiferença às realidades (nacionais, regionais, sociais, culturais...)" (AFONSO, 2007, p. 17) que as políticas de avaliação vêm adquirindo. $\mathrm{O}$ autor salienta ainda que "[...] esta aparente consensualidade [...] vem ampliando a eficácia legitimadora da avaliação e tornando mais difícil desmontar e pôr em questão a sua aparente e pretendida neutralidade" (AFONSO, 2007, p. 17).

$\mathrm{Na}$ mesma linha de críticas à onipresença da avaliação nas políticas e nas práticas educacionais, Alfredo Veiga-Neto (2013) cria a noção de "delírios avaliatórios" para problematizar o crescente crédito dado à avaliação e criticar “[...] a invasão das práticas avaliatórias por toda a parte" (VEIGA-NETO, 2013, p. 157).

Vários estados e municípios brasileiros construíram sistemas próprios de avaliação para seus sistemas de ensino gerando, muitas vezes, profusão e sobreposição de avaliações nas escolas, retirando, inclusive, tempo para o desenvolvimento de práticas curriculares voltadas ao ensino e à aprendizagem.

Por profusão de avaliações, entendemos o acúmulo de diferentes tipos e lógicas de avaliação, como, por exemplo, a prova montada pelo professor, as avaliações da secretaria à qual a escola esteja submetida e a avaliação de âmbito nacional, sem contar eventuais simulados e testes. Esse congestionamento de instrumentos avaliativos pode gerar, inclusive, reações, por parte dos sujeitos por elas afetados, opostas às desejadas por quem pensou aquela avaliação, como descaso, repulsa e negligência. Em relação à sobreposição de avaliações, referimo-nos a avaliações que possuam o mesmo desenho, implicando na obtenção dos mesmos resultados. $\mathrm{O}$ desenho de cada avaliação condiciona as possibilidades de realização de diagnósticos, seja sobre uma rede, seja sobre a escola ou sobre uma turma, ou individualmente sobre cada aluno.

O Saerjinho, que está atrelado a uma política de responsabilização educacional do governo fluminense, é aplicado bimestralmente a todos os alunos do Ensino Médio regular e a alunos das séries que finalizam as etapas anteriores do Ensino Fundamental, ou seja, $5^{\circ}$ e $9^{\circ}$ anos. No Ensino Médio, são objeto de avaliação os conhecimentos de Língua Portuguesa, Matemática, História, Geografia, Física, Química e Biologia. Embora o ano letivo na rede estadual do Rio de Janeiro seja dividido em quatro bimestres, o Saerjinho é aplicado somente nos três primeiros. Não encontramos nos documentos pesquisados justificativa alguma sobre a ausência de aplicação desse instrumento avaliativo no quarto bimestre.

Práxis Educativa, Ponta Grossa, p. 693-713, v. 11, n. 3, set./dez. 2016 Disponível em: <http://www.revistas2.uepg.br/index.php/praxiseducativa> 
Os resultados são disponibilizados individualmente para cada escola eletronicamente por meio do site do Centro de Políticas Públicas e Avaliação da Educação (CAEd), instituição que desenvolve e operacionaliza o sistema de avaliação do estado, e pode ser acessado por bimestre, disciplina, série, turma e aluno. É possível identificar o percentual de acertos de cada turma por disciplina, de cada habilidade ${ }^{2}$ por turma, e o que cada aluno acertou e errou, questão por questão.

Sendo, pois, o Saerjinho uma avaliação que compõe o sistema de avaliação do estado do Rio de Janeiro, interessa-nos perceber como essa política de avaliação tem sido justificada pela SEEDUC/RJ. Nesse sentido, recorremos às informações publicadas no site oficial da Secretaria:

[...] o programa tem como finalidade monitorar o padrão de qualidade do ensino e colaborar com a melhora da qualidade da educação. Os resultados de avaliações em larga escala como o SAERJ apresentam informações importantes para o planejamento de medidas em todos os níveis do sistema de ensino e funcionam como subsídio para ações destinadas a garantir o direito do estudante a uma educação de qualidade.

[...] os resultados dessas avaliações são complementares e, para que possam fazer a diferença na qualidade da educação oferecida, devem ser integrados ao cotidiano do trabalho escolar.

O Sistema de Avaliação bimestral Saerjinho ajudará a Secretaria de Estado de Educação a elaborar medidas para melhorar o processo de ensino na rede estadual. As provas serão aplicadas nas disciplinas de Língua Portuguesa, Matemática, Ciências (para $5^{\circ}$ e $9^{\circ}$ anos do Ensino Fundamental) e Química, Física e Biologia (para o Ensino Médio, Ensino Médio Integrado e Curso Normal) ${ }^{3}$. (RIO DE JANEIRO, 2014, grifos nossos).

As articulações discursivas mobilizadas em meio ao processo de significação do Saerjinho, presentes nos trechos extraídos de documentos oficiais, configuram-se em torno da questão da qualidade na/da educação. Concordando com Ramos (2014), observamos que "[...] a avaliação é tomada como instrumento regulatório da qualidade" (RAMOS, 2014, p. 51), pois, como se pode notar nas informações oficiais, ela serve para "[...] monitorar o padrão da qualidade de ensino" e tem o potencial de "[...] fazer a diferença na qualidade da educação oferecida" (RIO DE JANEIRO, 2014, grifos nossos).

Podemos, assim, pensar a política de avaliação fluminense como espaço hegemônico contingente de definição do que é e do que não é ensino de qualidade para as escolas que fazem parte da sua rede. Sendo o conhecimento o objeto a partir do qual se estabelecem as relações de ensino-aprendizagem, compreendemos que as políticas de avaliação são políticas que definem conhecimento de qualidade, isto é, aquele que é válido a ser ensinado nas escolas da Educação Básica.

Evidentemente, não há quem seja contrário à ideia de qualidade na educação, visto que esse termo denota sentidos positivos e desejáveis. No entanto, não há clareza sobre o que de fato se deseja quando se evoca a qualidade. Sousa (1997), refletindo sobre essa questão, afirma que qualidade

[...] não é "algo dado", não existe "em si”, remetendo à questão axiológica, ou seja, dos valores de quem produz a análise de qualidade. A emergência de critérios de avaliação não se dá de modo dissociado das posições, crenças, visão de mundo e práticas sociais de quem os concebe. É um conceito que nasce da perspectiva filosófica, social, política

\footnotetext{
${ }^{2}$ Cada habilidade contém objetivos específicos a serem atingidos em relação ao ensino de determinado conteúdo curricular das disciplinas avaliadas. Cada habilidade pode englobar mais de uma questão.

${ }^{3}$ A partir de 2013, o Saerjinho passou a contemplar também as disciplinas de História e Geografia.
}

Práxis Educativa, Ponta Grossa, p. 693-713, v. 11, n. 3, set./dez. 2016 Disponível em: <http://www.revistas2.uepg.br/index.php/praxiseducativa> 
de quem faz o julgamento e dela é expressão. Portanto, os enfoques e critérios assumidos em um processo avaliativo revelam as opções axiológicas dos que dele participam. (SOUSA, 1997, p. 26 apud SOUSA; OLIVEIRA, 2010, p. 802, grifos dos autores).

$\mathrm{Na}$ perspectiva das políticas de avaliação, são os resultados obtidos pelos alunos nas avaliações externas de larga escala que dão sentido ao conceito de qualidade. De forma direta, pode-se dizer que se os alunos vão bem nos testes padronizados, o ensino é de qualidade; se os alunos vão mal, o ensino não é de qualidade. Esse entendimento é bastante restrito por negligenciar fatores escolares e extraescolares que afetam o desempenho discente, como comprovam pesquisas na área de eficácia escolar (BROOKE; SOARES, 2008).

Para Candau (apud CARVALHO; PLETSCH, 2011), as avaliações deixam de fora aspectos sociais, culturais e políticos que são igualmente importantes à aprendizagem da Matemática, da Língua e das Ciências. Ademais, essa forma restrita de aferir qualidade tem por consequência a responsabilização docente em algum grau, o que serve de pretexto para a construção de discursos que aglutinem demandas de intervenção nos processos de ensino, afetando as práticas curriculares. Nesse caso, a centralidade da avaliação nas políticas de regulação da qualidade do ensino busca conferir legitimidade aos discursos que responsabilizam os docentes pelo fracasso educacional do país, pois as políticas de avaliação em larga escala têm se caracterizado por uma especialização e um refinamento técnico e metodológico que produz dados estatísticos confiáveis.

Nessa discussão, Traversini (2013) aponta que a forte presença dos números por meio da estatística faz com que as avaliações em larga escala adquiram "[...] um caráter moral que mobiliza sua aceitação, têm força de verdade, adquirem caráter de validade e inquestionabilidade e tornamse imperativos nas políticas educacionais e curriculares da atualidade" (TRAVERSINI, 2013, p. 179 , grifo da autora).

Para Santos (2013), os números exercem certo fetiche, polarizando as discussões e impedindo a problematização de outras questões mais difíceis de serem mensuradas. Santos (2013) destaca que:

Os números parecem neutros, verdades incontestáveis, mas na realidade são de natureza política, porque escolher o que medir e como medir é uma decisão de dimensão política, assim como o domínio da política é constituído por números. No entanto, devido à incontestável "objetividade" que os números parecem evidenciar, sua utilização termina despolitizando os debates que pressupõem julgamentos políticos. (SANTOS, 2013, p. 113).

Sendo, pois, da ordem do hegemônico nas políticas de avaliação a articulação entre qualidade na/da educação e os resultados obtidos pelos alunos nas avaliações externas de larga escala, críticos apontam para possíveis distorções nos processos educativos em decorrência da universalização dessa articulação: redução do currículo ao que é passível de mensuração; instauração de um movimento de competição que modifica as relações entre as escolas e destas com a comunidade; crescimento do absenteísmo docente (SANTOS, 2013); mudanças na subjetividade das pessoas (BALL, 2002); exclusão de alunos mais "fracos" dos processos avaliativos; treinamento dos alunos para os testes; fornecimento de respostas aos alunos das questões das provas (CASASSUS, 2009).

Consideramos pertinente sublinhar que o processo de significação que articula a qualidade na/da educação aos resultados dos alunos em testes padronizados não tenciona necessariamente promover as distorções apontadas e que elas possivelmente ocorrem, sendo estas, portanto, efeitos não desejados das políticas de avaliação, o que também não significa que 
não possam ser previstos. Nesse sentido, há, por parte daqueles que defendem a centralidade da avaliação nas políticas educacionais como forma de obter-se um ensino de qualidade (BROOKE; SOARES, 2008; SCHWARTZMAN, 2005), uma necessidade de intensificação de estudos em busca de medidas que possam estancar ou amenizar os efeitos não desejados das políticas de avaliação. Dessa forma, lutam contra os efeitos indesejados e não contra a política de avaliação. Nessa linha de reflexão, Schwartzman (2005) considera que:

\begin{abstract}
As avaliações de nova geração que surgiram em todo o mundo nas últimas décadas são tentativas mais ou menos bem-sucedidas de responder a problemas reais, e deverão continuar a existir, apesar de seus eventuais problemas e dificuldades. Não é que as avaliações consigam atender a todas as questões que preocupam; mas os problemas associados às avaliações parecem ser claramente preferíveis aos problemas associados à sua não existência, como falta de parâmetros, a ausência de critérios, os desperdícios e injustiças na distribuição de recursos e a impossibilidade de estabelecer políticas consistentes para sistemas de educação de massas. (SCHWARTZMAN, 2005, p. 31).
\end{abstract}

Há também de destacar-se que esses efeitos não são universais a todos os desenhos de políticas de avaliação, gerando a necessidade de análises específicas. Ao produzir efeitos sobre questões como ensino, organização e seleção de conteúdos, práticas docentes, subjetivações docentes e discentes, dentre outros aspectos curriculares, as políticas de avaliação da / ha Educação Básica têm servido como espaço de legitimação do conhecimento que se quer ensinado pelos professores e aprendido pelos alunos. $\mathrm{Na}$ seção seguinte, discutiremos as tensões em torno do conhecimento histórico validado a ser ensinado nas escolas fluminenses.

\title{
Saerjinho: território de disputa por sentidos de conhecimento histórico escolar
}

A questão do conhecimento atravessa tensões que se fazem presentes ao longo da trajetória do campo do Currículo e são permanentemente reatualizadas. Contudo, não é escopo deste texto entrar nessa discussão. Interessa-nos aqui explicitar o significado de conbecimento escolar com o qual operamos neste estudo, sublinhando a dimensão política que esse termo carrega.

Resultante de articulações discursivas produzidas em meio a disputas que envolvem diferentes interesses e demandas, o conhecimento escolar apresenta-se, em nosso entendimento, como um objeto de reflexão incontornável na agenda política educacional contemporânea. Em cada política curricular, e Saerjinho é uma delas, hegemonizam-se contingencialmente sentidos desse significante. Em meio a essas articulações discursivas produzidas no cenário político e acadêmico da atualidade, é possível identificar a presença recorrente de práticas articulatórias que tendem a hegemonizar o sentido de conteúdo como sendo universal, engessado, neutro, a-histórico, portanto imune a qualquer problematização. Nessas cadeias de equivalência, tende-se ora a reatualizar a perspectiva conteudista, ora reforçar o que Veiga-Neto (2012) nomeou de conteudofobia, produzindo efeitos políticos e epistemológicos nos debates curriculares em curso.

Em oposição a essas duas perspectivas de análise, Gabriel e Moraes (2014) defendem que o conteúdo se configura como uma unidade diferencial, dentre outras que se articulam, para configurar o conhecimento escolar. Como tal, a fixação de seu sentido é relacional, precária e provisória. Isso significa que, embora o significante conteúdo seja portador de estabilidades de sentido historicamente construídas, nada impede que esse sentido hegemônico, em função dos interesses em jogo, seja desestabilizado e deslocado.

Essa leitura permite simultaneamente a não reduzir conbecimento escolar a conteúdos e operar com outras cadeias de equivalência definidoras desses termos que podem abrir pistas teóricas para enfrentar algumas aporias presentes nos debates curriculares. Afinal, como lidar, por 
exemplo, com o valor de verdade de que nos fala Forquin (1993) quando se trata de pensar o processo de produção do conhecimento escolar após as críticas à racionalidade iluminista hegemonizada no paradigma da modernidade? Como continuar operando com a racionalidade científica após a desestabilização do sentido hegemônico de verdade em torno da qual ela se forjou?

$\mathrm{Na}$ perspectiva aqui defendida, o que está em jogo é a possibilidade de operar com articulações discursivas que permitam ensaiar respostas teóricas para esse tipo de questionamento. Nesse movimento, o termo conteúdo, percebido como uma unidade diferencial na cadeia de equivalência em torno do significante conbecimento escolar pode ser ressignificado como portador de interesses diretamente relacionados à produção do conbecimento cientificico , em particular no que concerne ao comprometimento desse último com os regimes de verdade das diferentes áreas disciplinares.

Desse modo, é esse "conhecimento científico curricularizado e/ou didatizado" (GABRIEL; CASTRO, 2013, p. 101), “[...] produzido e legitimado em função dos respectivos regimes de verdade das diferentes áreas disciplinares" (GABRIEL; MORAES, 2014, p. 32) que estamos nomeando como conteúdo. A presença da unidade diferencial conteúdo, na cadeia equivalencial definidora de conhecimento escolar, implica reconhecimento dos fluxos de cientificidade $^{5}$ na produção daquilo que é considerado válido a ser ensinado nas escolas da Educação Básica. Tal presença não é resultado de uma decisão individual, mas é um jogo sem começo e sem fim estabelecido previamente ao próprio jogo que é, no entanto, jogado pelos atores envolvidos.

A história escolar não é tomada aqui como algo menor em relação ao conhecimento produzido academicamente, mas um conhecimento com especificidades epistemológicas que, em seu processo de construção, entra em contato com vários outros saberes para tornar-se possível de ser ensinada. O desafio que se coloca é o de fazer com que a reelaboração didática preserve os fluxos de cientificidade, garantindo que o conhecimento produzido e ofertado na e para a escola seja também "poderoso" apesar dos regimes distintos de produção do passado.

No caso da disciplina História, essa relação torna-se mais latente à medida que tradicionalmente lhe são imputadas, e aceitas, fortes demandas axiológicas, tanto em termos políticos como culturais. Gabriel e Monteiro (2014), nesse sentido, salientam que:

Se o processo de axiologização é inerente a todo processo de produção dos conhecimentos escolares, correspondendo, como afirma Develay (1995), a uma "ética implícita", defendemos que, no caso dos saberes em História, esse processo se apresenta de maneira mais sistemática, muitas vezes de forma explícita, estando presente tanto no seio do próprio saber histórico-acadêmico como em todas as instâncias em que se opera sua reelaboração. $\mathrm{Na}$ Academia, na "transposição externa" (noosfera) ou na "transposição interna" (sala de aula), o saber histórico é encenado a partir de escolhas que diferem e se orientam em função da afinidade dos autores envolvidos (pesquisadores, autores de propostas curriculares, de livros didáticos,

\footnotetext{
${ }^{4}$ Isso implica igualmente em problematizar as fixações hegemônicas desse significante. Com efeito, o sentido de conhecimento científico tende a ser apropriado, nos debates educacionais, ora como panaceia para superar os desafios de uma escola de qualidade, ora como "fonte de todos os males" que assolam o processo de democratização das instituições escolares. Essas leituras operam com o sentido hegemonizado de ciência que a associa ao lugar da verdade cristalizada inquestionável produzida no mundo ocidental pela razão iluminista. Essa fixação tomada como previamente estabelecida subjaz os processos de significação que disputam projetos de escola e são apropriadas politicamente por diferentes grupos formuladores de demandas de igualdade e de diferença.

${ }_{5}^{5}$ Operar com a ideia de fluxos de cientificidade na definição de conhecimento escolar significa afirmar o interesse em trazer para o debate curricular articulações discursivas que resultam de práticas articulatórias produtoras de cadeias de equivalência nas quais participe também um sentido de conhecimento científico.
}

Práxis Educativa, Ponta Grossa, p. 693-713, v. 11, n. 3, set./dez. 2016 Disponível em: <http://www.revistas2.uepg.br/index.php/praxiseducativa > 
professores) com as diversas matrizes teóricas e axiológicas por eles privilegiadas. (GABRIEL; MONTEIRO, 2014, p. 36, grifos das autoras).

O conhecimento histórico fixado no Saerjinho configura-se como a "fina flor dos validados" (ROCHA, 2013) no âmbito do estado do Rio de Janeiro, dado o caráter de seleção intrínseco à elaboração de qualquer tipo de instrumento avaliativo educacional.

Para fazer a análise proposta, organizamos as questões a partir de três eixos de discussão ${ }^{6}$ : a questão temporal (a partir da divisão clássica da linha do tempo), a espacialidade (Brasil, América, África ou Europa) e o foco em dimensões do social (política, economia ou sociedade/cultura) ${ }^{7}$. Consideramos essa organização dos itens da prova de História do Saerjinho potente para identificar o conhecimento histórico validado a ser ensinado nas escolas fluminenses.

Foram aplicadas entre 2013 e 2014 seis edições do Saerjinho. No entanto, as últimas provas aplicadas em 2014 não se encontravam disponíveis até o momento da escrita deste artigo. Dessa forma, o corpo empírico relativo às provas contempla cinco edições. Privilegiamos as turmas de Ensino Médio, considerando, portanto, as cinco avaliações disponíveis e as três séries desse segmento. Há, assim, um total de 15 provas, sendo cinco de cada série. Cada instrumento avaliativo possui nove questões de História, o que totaliza 135 itens.

Para efetuar a organização das questões em relação ao primeiro eixo, organizamos o conteúdo nos limites temporais estabelecidos pela periodização clássica hegemonizada na cultura histórica escolar, gerando o Quadro 1 a seguir":

Quadro 1 - Classificação das questões do Saerjinho a partir da periodização clássica

\begin{tabular}{|c|c|c|c|c|}
\hline TEMPO/SÉRIE & $\mathbf{1}^{\mathbf{0}}$ ANO & $\mathbf{2}^{\mathbf{0}}$ ANO & $\mathbf{3}^{\mathbf{0}}$ ANO & TOTAL \\
\hline Escrita da História/Ofício do Historiador & 6 & 1 & 2 & 9 \\
\hline Pré-História & - & - & - & 6 \\
\hline Idade Antiga & 6 & - & - & 10 \\
\hline Idade Média & 9 & 1 & - & 46 \\
\hline Idade Moderna & 23 & 23 & - & 63 \\
\hline Idade Contemporânea & - & 20 & 43 & 6 \\
\hline
\end{tabular}

Fonte: Elaborado pelos autores.

O Quadro 1 corrobora a afirmação de Araújo (2012) de que há “[...] uma organização curricular marcada por uma perspectiva temporal linear e progressiva como parte de uma tradição disciplinar que tem resistido aos processos de mudança vividos pelo ensino de História" (ARAÚJO, 2012, p. 17).

Há uma clara divisão dos tempos históricos por série e em uma perspectiva linear, que sugere um acontecimento necessariamente após o outro, desconsiderando, assim, as múltiplas

\footnotetext{
${ }^{6}$ Os eixos estabelecidos para a análise representam apenas uma dentre tantas possibilidades de foco para aspectos tão complexos e caros à estrutura do conhecimento histórico como temporalidades, espacialidades e dimensões do social.

${ }^{7}$ A classificação das questões em cada um dos eixos estabelecidos foi feita a partir dos textos que serviam de referência para o comando de cada questão.

${ }^{8}$ As questões do $1^{\circ}$ ano totalizam 44, e não 45 como as demais. Isso se justifica pela impossibilidade de classificar uma das questões dentro dos recortes temporais estabelecidos, considerando o texto de apoio, o comando da questão e as opções de resposta.
} 
possibilidades de entendimento dos eventos históricos como fruto de causalidades diversas que se entrelaçam no processo de construção de sentidos. Ademais, esse mesmo Quadro aponta o privilégio conferido neste instrumento avaliativo a conteúdos do período pós Revolução Francesa. Esse dado indica a reafirmação de uma tradição do ensino de História em privilegiar temáticas relacionadas ao desenvolvimento do modo capitalista de produção (BITTETENCOURT, 2001).

Puxando o segundo eixo de discussão, a divisão espacial das questões (Quadro 2) oferece pistas para pensar a tensão universal e particular na hegemonização de conteúdos históricos no instrumento avaliativo oficial aqui privilegiado.

Quadro 2 - Classificação das questões do Saerjinho pelo viés espacial

\begin{tabular}{|c|c|c|c|c|}
\hline ESPAÇO/SÉRIE & $\mathbf{1}^{\mathbf{0}}$ ANO & $\mathbf{2}^{\mathbf{0}}$ ANO & $\mathbf{3}^{\mathbf{0}}$ ANO & TOTAL \\
\hline História do Brasil & 2 & 12 & 19 & 33 \\
\hline História da América & 2 & 5 & 10 & 17 \\
\hline História da África & 2 & - & 1 & 3 \\
\hline História da Europa & 34 & 26 & 15 & 75 \\
\hline
\end{tabular}

Fonte: Elaborado pelos autores.

De imediato, constata-se a perspectiva eurocêntrica do conhecimento histórico escolar validado a ser ensinado nas escolas estaduais do Rio de Janeiro. Essa tradição, apesar de sofrer críticas sobre seu aspecto colonialista de conhecimento, mantém-se hegemônica. Esteban (2010), que pesquisa sobre avaliação em uma perspectiva teórica pós-colonial, considera que

[...] o fim do período colonial como relação política não representou o fim do colonialismo como relação social, portanto a colonialidade do poder, do saber e do ser se mantém e adquire novas formas, se inserindo em novos projetos globais, consoantes à hegemonia, também epistemológica. (ESTEBAN, 2010, p. 47-48).

A perspectiva eurocêntrica não se evidencia apenas pelo predomínio de itens de prova relacionados à História da Europa, mas também à forma como são produzidas outras narrativas tendo como referência o eurocentrismo. Na questão a seguir (Figura 1), por exemplo, a narrativa que compõe o texto de referência articula processos conjunturais da realidade político-social brasileira anterior ao golpe civil-militar de 1964; no entanto, o comando da questão subordina essa narrativa à Guerra Fria, enfatizando uma relação de causa e efeito que tende a reforçar essa perspectiva. 
Figura 1 - Questão Saerjinho, $3^{\circ}$ ano, $3^{\circ}$ bimestre de 2013

\section{Leia o texto abaixo.}

[...] A crise política se arrastava desde a renúncia de Jânio Quadros em 1961. O vice de Jânio era João Goulart, que assumiu a presidência num clima político adverso. O governo de João Goulart (1961-1964) foi marcado pela abertura às organizações sociais. Estudantes, organizações populares e trabalhadores ganharam espaço, causando a preocupação das classes conservadoras como, por exemplo, empresários, banqueiros, militares e classe média. Todos temiam uma guinada do Brasil para o lado socialista. Vale lembrar, que neste período, o mundo vivia o auge da Guerra Fria. [...]

Disponível em: <http://www.suapesquisa.com>. Acesso em 26 mar. 2013. Fragmento.

De acordo com esse texto, a Guerra Fria foi um processo histórico que contribuiu para a eclosão

A) da Ditadura Militar.

B) da República das Espadas.

C) da Revolta da Armada.

D) do Estado Novo.

E) do Movimento tenentista.

Fonte: Rio de Janeiro (2013, p. 16).

Percebemos, também a partir do Quadro 2, que as demandas contemporâneas pelo ensino de História da África, embora contempladas no Saerjinho, ocupam uma posição de marginalidade, representando, pois, menos de $3 \%$ de todos os itens de prova disponíveis. Ademais, quando aparece no instrumento avaliativo, é em uma perspectiva de relação com a História do Brasil, diferentemente de várias questões sobre a História da Europa que se fazem presentes sem necessariamente estabelecer relação com o Brasil, reforçando a perspectiva colonialista denunciada por Esteban (2010).

As narrativas de africanidade são produzidas de forma subordinada à História do Brasil, mostrando que a colonialidade do poder na produção das narrativas históricas escolares não ocorre apenas a partir da Europa como centro a partir do qual todas as explicações são validadas, mas circula em outras escalas, revelando, assim, a multiplicidade de possibilidades políticas de fixação de significados. Dessa forma, é possível perceber que a ocupação de posições de subordinação não é fixa e determinada a priori, mas definidas no jogo político da fixação de significados das narrativas históricas no Saerjinho.

O Quadro 2 aponta, também, o pouco destaque conferido a questões de História da América (representam pouco mais de 10\% do total), o que serve como indício para pensar sobre as tensões entre projetos curriculares a partir de demandas pela construção de uma identidade regional no âmbito do MERCOSUL (OLIVEIRA, 2010), o que merece investimentos futuros de pesquisa, não cabendo, portanto, nos limites deste texto.

Não há discrepância relevante que aponte para uma estabilidade significativa em relação ao foco na História dos Estados Unidos ou da América Latina, pois, das 17 questões, dez versam sobre esta última, enquanto sete referem-se à História dos Estados Unidos.

Ainda em relação ao Quadro 2, percebe-se que apenas no $3^{\circ}$ ano a História europeia não é hegemônica, embora apresente uma diferença pequena em relação à História do Brasil $(19 \mathrm{x}$ 15), a qual predomina. Além disso, em algumas questões, tal como a que mostramos na Figura 1, a lógica da História da Europa faz-se presente, de alguma forma, nas questões que aqui foram classificadas como sendo de História do Brasil. 
Detalhando a presença da História do Brasil no Saerjinho, encontra-se o Quadro $3^{9}$ a seguir.

Quadro 3 - Classificação das questões de História do Brasil do Saerjinho

\begin{tabular}{|c|c|c|c|c|}
\hline $\begin{array}{c}\text { HISTÓRIA DO } \\
\text { BRASIL/SÉRIE }\end{array}$ & $\mathbf{1}^{\mathbf{o}}$ ANO & $\mathbf{2}^{\mathbf{o}}$ ANO & $\mathbf{3}^{\mathbf{o}}$ ANO & TOTAL \\
\hline Colônia & 2 & 9 & - & 11 \\
\hline Império & - & 2 & 1 & 3 \\
\hline República & - & - & 17 & 17 \\
\hline
\end{tabular}

Fonte: Elaborado pelos autores.

O destaque conferido ao período republicano da História brasileira pode ser um indício que reforça o argumento explicitado anteriormente referente ao predomínio de questões relacionadas à "saga" do capitalismo em seu processo de consolidação no país. Chama atenção a posição ocupada pelo período colonial em comparação ao período imperial, o que pode indicar a permanência da força da perspectiva eurocêntrica na produção historiográfica nacional, com ênfase em determinados processos em detrimento de outros.

Partindo, pois, para o terceiro eixo de discussão sobre os itens de História nas provas do Saerjinho, apresentamos a divisão das questões de acordo com o foco em algumas dimensões do social (Quadro 4):

Quadro 4 - Classificação das questões do Saerjinho por dimensões do social

\begin{tabular}{|c|c|c|c|c|}
\hline ESTRUTURA/SÉRIE & $\mathbf{1}^{\mathbf{o}}$ ANO & $\mathbf{2}^{\mathbf{o}}$ ANO & $\mathbf{3}^{\mathbf{o}}$ ANO & TOTAL \\
\hline Política & 12 & 19 & 35 & 66 \\
\hline Economia & 8 & 13 & 1 & 22 \\
\hline Sociedade/Cultura & 22 & 13 & 8 & 43 \\
\hline
\end{tabular}

Fonte: Elaborado pelos autores.

A classificação apresentada no Quadro 4 foi estabelecida a partir da análise dos conteúdos históricos privilegiados nos textos de referência que compunham as questões, reconhecendo que, em algumas situações, torna-se difícil estabelecer distinções significativas entre as referidas dimensões do social.

O Quadro 4 aponta para a permanência neste campo curricular da tradição da história política como responsável pelo ritmo da história nacional recontextualizada nas questões do Saerjinho. Há de destacar-se, porém, que a presença ostensiva do foco político neste instrumento avaliativo não significa uma valorização dos grandes heróis, tampouco de seus "grandes feitos", como os historiadores dos Annales denunciavam que se fazia até o início do século XX. Os sujeitos sociais são tomados em uma perspectiva de construção social em meio ao jogo político, como pode ser percebido na questão a seguir (Figura 2).

\footnotetext{
${ }^{9}$ O Quadro 2 aponta 33 itens de História do Brasil, mas pela impossibilidade de classificar dois destes itens de acordo com a divisão estabelecida no Quadro 3, o total apresentado neste é de 31 questões.
}

Práxis Educativa, Ponta Grossa, p. 693-713, v. 11, n. 3, set./dez. 2016 Disponível em: <http://www.revistas2.uepg.br/index.php/praxiseducativa $>$ 
Figura 2 - Saerjinho, $2^{\circ}$ ano, $3^{\circ}$ bimestre de 2013

$\begin{array}{ll}\text { Questão } 29 & \text { H110011RJ }\end{array}$

Leia o texto e observe a imagem abaixo.

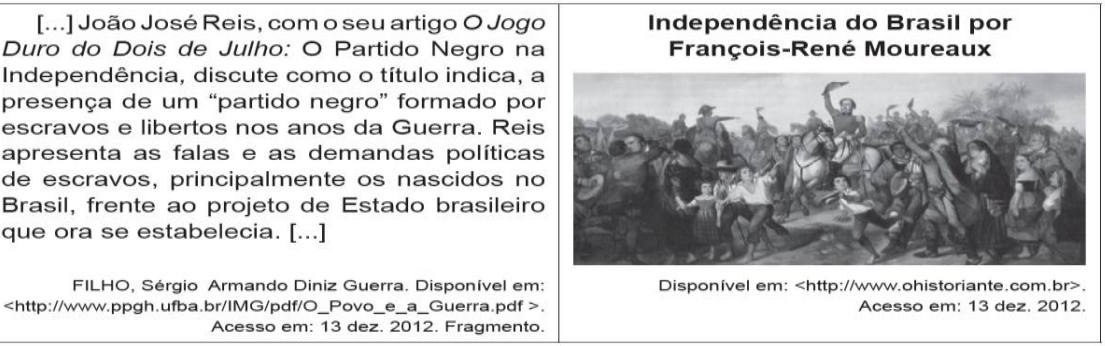

Qualé oaspecto destacado sobrea independência do Brasil, nesse texto enessa imagem, respectivamente?

A) A participação dos escravos e a valorização de D. João VI.

B) A participação dos escravos e a valorização de D. Pedro I.

C) A participação dos escravos e a valorização do ato de D. Pedro II.

D) A presença portuguesa e a valorização de Deodoro da Fonseca.

E) A presença portuguesa e a valorização do ato de Tiradentes.

Fonte: Rio de Janeiro (2013, p. 14).

É relevante também que o foco na estrutura econômica ocupe a última posição dentre os três focos construídos para classificação das questões. Esse dado pode ser um indício do enfraquecimento do marxismo como opção teórico-política na construção de narrativas históricas para o espaço escolar, merecendo também análises mais aprofundadas que escapam a este artigo.

O mapeamento das questões de História do Saerjinho, a partir dos três eixos de discussão estabelecidos, apontou para uma hegemonização/validação do sentido de conhecimento histórico escolar marcado pelo viés eurocêntrico e linear com foco nos eventos políticos. Apesar de haver demandas por outras formas de produção e distribuição do conhecimento histórico na/para as escolas da Educação Básica, estas não foram ainda capazes de articularem-se a ponto de produzir outras hegemonias.

Esses sentidos de conhecimento histórico que estão fixados no Saerjinho encontram-se em permanentes disputas, nas quais docentes que ministram essa disciplina escolar participam do jogo político produzindo demandas que interpelam de formas diversas as fixações em uma política de avaliação, e seu papel no processo de fixação de sentidos. Assim, interessa-nos aqui apresentar algumas mobilizações de docentes de História tendo como referência a presença dessa disciplina na política de avaliação aqui privilegiada.

Conforme vimos defendendo, a produção do conhecimento escolar contempla também questões axiológicas que se articulam aos conteúdos no processo de transformação de um objeto de investigação em um objeto de ensino. Em relação à disciplina História, a questão dos valores é ainda mais latente, fazendo parte da estrutura epistemológica desse conhecimento, e os professores explicitam essa preocupação com a formação "política" de seus alunos, como é possível perceber nos excertos abaixo:

[...] em História, o que você quer é que o sujeito seja um cidadão crítico, um sujeito capaz de discernir...mesmo que ele opte por um pensamento completamente divergente do seu, que ele se sinta fortalecido nessa opção, né?! (Prof. ${ }^{a}$ Helena, grifos nossos).

Aí, se você também for para uma outra proposta, uma proposta de educação onde a ideia é politizar a pessoa, incentivar a pessoa para as questões do meio dela, então você também não pode dar o Currículo Mínimo. (Prof. ${ }^{a}$ Rosa, grifos nossos).

Práxis Educativa, Ponta Grossa, p. 693-713, v. 11, n. 3, set./dez. 2016 Disponível em: <http://www.revistas2.uepg.br/index.php/praxiseducativa > 
[...] o que eu espero é que o aluno se veja como um agente, realmente, capaz de transformar o mundo, que ele se veja uma pessoa importante, se veja como um sujeito capaz de ser inserido num grupo e entender as necessidades desse grupo, como um todo. Porque eu acho que o mundo tá muito individualista. Eu acho que a gente tem que pensar também no coletivo, eu penso assim. (Prof. ${ }^{a}$ Rita, grifos nossos).

O sentido de conhecimento histórico escolar mobilizado nessas falas docentes é o de produzir "subjetividades rebeldes" (GABRIEL, 2011). Velasco (2013) aponta, em pesquisa que investiga sentidos de "aluno crítico", que esse termo está vinculado à contestação da ordem e ausência de passividade.

Contudo, sendo o conteúdo uma unidade diferencial importante na produção desse conhecimento, interessa-nos investigar qual o lugar atribuído a esse significante no processo de formação "política" dos alunos. Os limites desse texto não permitem investigações desse aspecto com a devida acuidade, mas deixamos uma "porta entreaberta" a partir das falas de algumas docentes como, por exemplo, a Prof." Rosa que considera que "[...] se a ideia é politizar a pessoa [...] você também não pode dar o Currículo Mínimo”. Ao fazer essa afirmação, a docente entende que nem todo conteúdo é potencialmente produtivo para promover o senso crítico e fomentar a politização discente. Dessa forma, a docente deseja parâmetros outros no processo de seleção do que ensinar sem, contudo, apontar que características os conteúdos dessa disciplina devem possuir para serem legitimados a ser ensinados nas aulas de História da Educação Básica. pesquisa:

São diversos os sentidos de conteúdo mobilizados pelos docentes que participaram da

[...] a minha maior dificuldade de História hoje é o conteúdo mesmo que ele tá vendo, porque ele baixa na internet...hoje tem um mecanismo né, de acesso a essa informação, a grande maioria, que ele pode ter esse conteúdo melhor, mas como é que eu vou utilizá-lo, né? (Prof. Ana, grifos nossos).

[...] na verdade o conteúdo exigido pelo Saerj é um conteúdo tradicional, é um conteúdo de cronologia e de conteudista, conteudista no sentido de factual. Então não há uma exigência de pensar, de exigir pensamento de criticidade aos alunos. (Prof. ${ }^{a}$ Cecília, grifos nossos).

A Professora Ana, ao afirmar que os alunos podem baixar da internet o conteúdo de História que seria ministrado nas aulas e mostrar preocupação com isso, revela que cabe ao professor atribuir sentido ao conteúdo que está sendo ensinado, conforme expresso na frase "ele pode ter esse conteúdo melhor". Nesse sentido, não é o conteúdo que possui um potencial de politização intrínseco, mas o processo de recontextualização didática feito no âmbito da sala de aula é que deve ser capaz de produzir e atribuir sentidos.

Essa percepção da Prof. ${ }^{a}$ Ana encontra eco em Monteiro (2002), para quem nas aulas de História o fio de sentido é dado por quem narra: o professor. Ademais, a preocupação revelada com o conteúdo articulada à questão da atribuição de sentidos pelo professor vai ao encontro da aposta política aqui defendida de garantia dos fluxos de cientificidade no conhecimento escolar sem que se reduza esse conhecimento aos conteúdos.

A fala da Prof. ${ }^{a}$ Cecília expressa uma preocupação com a configuração epistemológica do conhecimento histórico, objeto de avaliação no Saerjinho. Ao denunciar o viés cronológico e factual dos conteúdos presentes no instrumento avaliativo do estado, a docente deseja expelir para fora da cadeia equivalencial definidora do "bom" conhecimento histórico esses elementos que ela considera inapropriados para atingir o objetivo de tornar o aluno um cidadão crítico.

Práxis Educativa, Ponta Grossa, p. 693-713, v. 11, n. 3, set./dez. 2016 Disponível em: <http://www.revistas2.uepg.br/index.php/praxiseducativa > 
Um elemento que emergiu nas falas das docentes entrevistadas como fator relevante para o ensino/aprendizagem/avaliação no ensino de História é a questão da interpretação:

\begin{abstract}
Se ele consegue saber pensar, entender, interpretar, é muito melhor do que saber decorar um monte de coisas. (Prof. ${ }^{a}$ Beatriz, grifos nossos).

Mesmo a questão de múltipla escolha, ela tem que ter um texto ali de referência para ele interpretar ali. (Prof. Ana, grifos nossos).

[...] saber contextualizar, saber ter o pensamento de uma época e fazer a transposição para época atual. Sabendo que nem tudo você pode transpor para o presente, mas que ele seja capaz de analisar os fatos, interpretar como eles aconteceram, saber a participação individual e coletiva da sociedade. Tanto é que nas minhas avaliações não há cobrança de datas, não há cobranças de época, mas sim a interpretações dos fatos. (Prof. ${ }^{a}$ Cecilia, grifos nossos).
\end{abstract}

Apesar da presença relevante nas articulações discursivas mobilizadas pelas docentes de História para significar o conhecimento histórico escolar, parece-nos que o termo interpretação não possui um consenso sobre seu uso, assumindo, assim, sentidos diversos, podendo ser pensado ora como atribuição de sentido sobre algo, como na fala da Prof. ${ }^{a}$ Cecília, ora sendo tomada como tradução, como os trechos das professoras Ana e Beatriz exemplificam.

A ausência do conteúdo nas questões de História da avaliação bimestral da SEEDUC/RJ, na forma como ele aqui tem sido concebido, está expressa nas seguintes falas:

[...] a prova de História é um pouco diferente das provas das exatas, porque há uma possibilidade de o aluno fazer mesmo que ele não tenha dado todo o conteúdo, porque é muita interpretação. Os textos são muito curtos, então o aluno que tem uma certa capacidade de interpretação, ele consegue dar um "chute" lógico, e responder algumas coisas. (Prof. ${ }^{a}$ Rosa, grifos nossos).

A parte de Humanas, a gente percebe que eles estão tentando fazer um estilo bem ENEM, uma coisa mais de interpretação, mas a parte de cálculo, de Exatas, eles não conseguem fazer isso. (Prof. ${ }^{a}$ Rosa, grifos nossos).

[...] a dificuldade exigida pelo Saerjinho é muito fora da realidade, não fora da realidade de exigência, mas que deixa de exigir ao alunado. São perguntas muito simples [...]. (Prof. ${ }^{a}$ Cecilia, grifos nossos).

É possível inferir que a demanda de professores de História da Educação Básica pela presença da interpretação na cadeia equivalencial do conhecimento histórico escolar é uma demanda que se encontra satisfeita no Saerjinho. No entanto, da forma que ela é articulada nessas cadeias equivalenciais, tende a colocar em posição de subalternidade os conteúdos específicos dessa área disciplinar.

As falas docentes aqui trazidas valorizam a questão axiológica e a interpretação no jogo político da definição dos elementos, considerados incontornáveis do ensinar/aprender/avaliar em História. A presença de questões de temporalidade e dos conteúdos não está garantida na cadeia equivalencial definidora do que é considerado validado a ser ensinado e, portanto, avaliado nas aulas de História do estado do Rio de Janeiro, ora sendo expelidos dessa cadeia, ora assumindo sentidos que enfraquecem seus potenciais políticos na configuração do conhecimento histórico escolar.

\title{
Considerações finais
}

Procuramos discutir neste artigo como as políticas de avaliação se constituem como políticas curriculares à medida que se configuram como espaço privilegiado de legitimação do que 
é válido a ser ensinado nas escolas. Defendemos aqui que as fixações de sentido estão em permanentes disputas e que sujeitos posicionados como docentes participam do processo de significação das políticas de avaliação e de sua relação com questões curriculares, como, por exemplo, o conhecimento.

A discussão política com a qual os professores se identificam tende a remeter à questão da relação com o conhecimento e não sobre o conhecimento. Em outros termos, o que está sendo questionado não é o que do conhecimento histórico fixado nas provas do Saerjinho, mas o quem do direito de fixar tal conhecimento em um instrumento avaliativo. Assim, a autonomia docente é evocada mais como princípio do que como estratégia ou garantia de mudanças na configuração do conhecimento histórico validado a ser ensinado e avaliado nas escolas públicas do estado do Rio de Janeiro.

As narrativas históricas hegemonizadas no Saerjinho reproduzem tradições dessa disciplina escolar como o foco nas questões políticas em uma perspectiva temporal linear, atrelada à ideia de progresso e de viés eurocêntrico. Chamou nossa atenção que, nas articulações discursivas das quais participam os docentes para significar o conhecimento histórico escolar que seria validado a ser ensinado nas escolas da rede estadual do Rio de Janeiro, novas abordagens da temporalidade não se constituem como unidade diferencial suficientemente potentes para entrar no jogo da definição do que seja uma avaliação "guardiã" da qualidade do processo de ensinoaprendizagem em História.

A queixa presente em algumas falas em relação aos itens presentes na prova de História do Saerjinho é sobre seu aspecto "conteudista", enfraquecendo o potencial político do termo conteúdo como momento da cadeia definidora do significante conhecimento escolar. Com efeito, nas cadeias de equivalência reatualizadas no momento da entrevista com os docentes, foi possível identificar articulações entre os termos valores e conteúdos no processo de definição do conhecimento histórico escolar que tendem a subalternizar o segundo significante em relação ao primeiro.

Apesar da crítica ao conteudismo do Saerjinho, não foi possível identificar nas falas docentes qualquer demanda pela inclusão, pela subtração ou pela substituição de conteúdos, o que pode revelar ausência de discordância em relação ao conteúdo presente no instrumento avaliativo. Logo, a crítica docente recai sobre a presença ostensiva dos conteúdos na prova e não sobre os conteúdos ali presentes, sendo a questão dos valores o que se deseja ampliar nessa avaliação.

No processo articulatório do que é considerado pelos professores de História incontornável no processo de ensinar/aprender/avaliar nessa disciplina, as principais unidades diferenciais articuladas foram as questões axiológicas e a noção de interpretação, sendo, portanto, os conteúdos deslocados para uma posição de subalternidade.

\section{Referências}

AFONSO, A. J. Estado, políticas educacionais e obsessão avaliativa. Contrapontos, Itajaí, v. 7, n. 1, p. 11-22, jan./abr. 2007.

ARAÚJO, C. M. Por outras histórias possíveis: em busca de diálogos interculturais em livros didáticos de histórias. 2012. 176 f. Tese (Doutorado em Educação) - Pontifícia Universidade Católica do Rio de Janeiro, Rio de Janeiro, RJ, 2012. 
BALL, S. J. Reformar escolas/reformar professores e os terrores da performatividade. Revista Portuguesa de Educação, Braga, v. 15, n. 2, p. 3-23, 2002.

BITTENCOURT, C. Capitalismo e cidadania nas atuais propostas curriculares de História. In: BITTENCOURT, C. (Org.). O saber histórico na sala de aula. 4. ed. São Paulo: Contexto, 2001. p. 11-27.

BROOKE, N.; SOARES, J. F. Pesquisa em eficácia escolar: origem e trajetórias. Belo Horizonte: UFMG, 2008.

BURITY, J. A. Discurso, política e sujeito na teoria da hegemonia de Ernesto Laclau. In: MENDONÇA, D.; RODRIGUES, L. P. (Orgs.). Pós-estruturalismo e teoria do discurso: em torno de Ernesto Laclau. Porto Alegre: EdPUCRS, 2008. p. 35-51.

BURITY, J. A. Teoria do discurso e educação: reconstruindo o vínculo entre cultura e política. Revista Teias, Rio de Janeiro, v. 11, n. 22, p. 7-29, maio/ago. 2010.

CARVALHO, C. R. de; PLETSCH, M. D. Entrevista por uma escola que reconheça as diferentes culturas presentes em seu contexto. Revista Teias, Rio de Janeiro, v. 12, n. 24, p. 279-284, jan./abr. 2011.

CASASSUS, J. Uma nota crítica sobre avaliação estandardizada: a perda da equidade e a segmentação social. Revista de Ciências da Educação, Americana, n. 9, p. 71-78, 2009.

ESTEBAN, M. T. Diferença, aprendizagens e avaliação: perspectiva pós-colonial e escolarização. In: ESTEBAN, M. T.; AFONSO, A. J. (Orgs.). Olhares e interfaces: reflexões críticas sobre a avaliação. São Paulo: Cortez, 2010. p. 45-70.

FERNANDES, D. Avaliar para aprender: fundamentos, práticas e políticas. São Paulo: UNESP, 2009.

FORQUIN, J. C. Escola e cultura: as bases sociais e epistemológicas do conhecimento escolar. Tradução Guacira Lopes Louro. Porto Alegre: Artmed, 1993.

FRAZÃO, E. E. V. Quem é o "povo brasileiro" que habita os livros didáticos de História? Um estudo a partir do campo do currículo. 2014. 163 f. Dissertação (Mestrado em Educação) Universidade Federal do Rio de Janeiro, Rio de Janeiro, RJ, 2014.

GABRIEL, C. T. Estudos curriculares face às demandas de nosso presente. Conferência do concurso público de provas e títulos para Professor Titular de Currículo. Faculdade de Educação, UFRJ, 2011.

GABRIEL, C. T. Conhecimento científico e currículo: anotações sobre uma articulação impossível e necessária. Revista Teias, Rio de Janeiro, v. 14, n. 33, p. 44-57, 2013 a.

GABRIEL, C. T. Discurso, demandas e fronteira: articulações teórico-metodológicas na análise de textos curriculares. Revista FAEEBA Educação \& Contemporaneidade, Salvador, v. 22, n. 40, p. 55-67, jul./dez. 2013b. 
GABRIEL, C. T.; CASTRO, M. M. Conhecimento escolar: objeto incontornável da agenda política educacional contemporânea. Revista Educação em Questão, Natal, v. 45, n. 31, p. 82110, jan./abr. 2013.

GABRIEL, C. T.; MONTEIRO, A. M. F. C. Currículo de História e narrativa: desafios epistemológicos e apostas políticas. In: MONTEIRO, A. M. F. C. et al. (Orgs.). Pesquisa em ensino de História: entre desafios epistemológicos e apostas políticas. Rio de Janeiro: Mauad X; FAPERJ, 2014.

GABRIEL, C. T.; MORAES, L. M. S. Conhecimento escolar e conteúdo: possibilidades de articulação nas tramas da didatização. In: GABRIEL, C. T.; MORAES, L. M. S. (Orgs.). Currículo e conhecimento: diferentes perspectivas teóricas e abordagens metodológicas. Petrópolis: De Petrus; FAPERJ, 2014. p. 23-42.

HOWARTH, D. Discourse. Buckinghtam: Open University Press, 2000.

LACLAU, E. La razón populista. Buenos Aires: Fondo de Cultura Económica, 2005.

LACLAU, E. Emancipação e diferença. Rio de Janeiro: EdUERJ, 2011.

LOPES, A. C.; MACEDO, E. Teorias de currículo. São Paulo: Cortez, 2011.

MACEDO, E. Currículo como espaço-tempo de fronteira cultural. Revista Brasileira de Educação, Rio de Janeiro, v. 11, n. 32, p. 285-296, mai./ago. 2006. DOI: 10.1590/s141324782006000200007

MARCHART, O. E1 pensamiento político posfundacional: La diferencia política em Nancy, Lefort, Badiou y Laclau. Buenos Aires: Fondo de Cultura Económica, 2009.

MARTINS, M. L. B. Avaliação e ensino de História. In: ENCONTRO REGIONAL DA ANPUH: Memória e Patrimônio, 14., 2010, Rio de Janeiro. Anais eletrônicos... Rio de Janeiro: UniRio, 2010. Disponível em: <http://www.encontro2010.rj.anpuh.org/resources/anais/8/1276663892_ARQUIVO_AVALI ACAOEENSINODEHISTORIA.pdf>. Acesso em: 12 jan. 2016.

MONTEIRO, A. M. F. C. Ensino de História: entre saberes e práticas. 2002. 256 f. Tese (Doutorado em Educação) - Pontifícia Universidade Católica do Rio de Janeiro, Rio de Janeiro, RJ, 2002.

OLIVEIRA, T. M. C. A política curricular de História no MERCOSUL: investigando discursos sobre "identidade regional". 2010. 138 f. Dissertação (Mestrado em Educação) Universidade Federal do Rio de Janeiro, Rio de Janeiro, RJ, 2010.

RAMOS, A. P. B. Conhecimento escolar e qualidade da educação nas políticas de avaliação da Educação Básica. 2014. 336 f. Tese (Doutorado em Educação) - Universidade Federal do Rio de Janeiro, Rio de Janeiro, RJ, 2014. 
RIO DE JANEIRO. Secretaria de Educação. Caderno X1101: $3^{\circ}$ Bimestre, Avaliação Diagnóstica, Ciências Humanas e Ciências da Natureza, 2 ${ }^{\circ}$ Ano do Ensino Médio. 2013. Disponível em: <http://bioeducacao.com.br/documents/X1101.pdf>. Acesso em: 10 jan. 2016.

RIO DE JANEIRO. Secretaria de Educação. Caderno X1201: $3^{\circ}$ Bimestre, Avaliação Diagnóstica, Ciências Humanas e Ciências da Natureza. 30 Ano do Ensino Médio. 2013. Disponível em: <http://bioeducacao.com.br/documents/X1201.pdf>. Acesso em: 14 jan. 2016.

RIO DE JANEIRO. Secretaria do Estado de Educação - SEEDUC. Educação. SAERJ/ SAERJINHO/ IDERJ. 2014.2 Disponível em: <http://www.rj.gov.br/web/seeduc/exibeconteudo?article-id=843535>. Acesso em: 14 jan. 2016.

ROCHA, A. A. C. N. Questionando o questionário: uma análise de currículo e sentidos de Geografia no ENEM. 2013. 323 f. Tese (Doutorado em Educação) - Universidade Federal do Rio de Janeiro, Rio de Janeiro, RJ, 2013.

SANTOS, L. L. C. P. As duas faces da avaliação. In: FAVACHO, M. P.; PACHECO, J. A.; SALES, S. R. (Orgs.). Currículo, conhecimento e avaliação: divergências e tensões. Curitiba: CRV, 2013. p. 109-122.

SCHWARTZMAN, S. As avaliações de nova geração. In: SOUZA, A. M. (Org.). Dimensões da avaliação educacional. Petrópolis, RJ: Vozes, 2005.

SOUSA, S. Z.; OLIVEIRA, R. P. Sistemas estaduais de avaliação: uso dos resultados, implicações e tendências. Cadernos de Pesquisa, São Paulo, v. 40, n. 141, p. 793-822, set./dez. 2010. DOI: 10.1590/S0100-15742010000300007

TRAVERSINI, C. S. Currículo e avaliação na contemporaneidade: há lugar para a diferença em tempos de imperativo dos números? In: FAVACHO, M. P.; PACHECO, J. A.; SALES, S. (Orgs.). Currículo, conhecimento e avaliação: divergências e tensões. Curitiba: CRV, 2013. p. 177-189.

VEIGA-NETO, A. É preciso ir aos porões. Revista Brasileira de Educação, Rio de Janeiro, v. 17, n. 50, p. 267-282, maio/ago. 2012. DOI: 10.1590/s1413-24782012000200002

VEIGA-NETO, A. Delírios avaliatórios: o currículo desvia para a direita ou um farol para o currículo. In: FAVACHO, M. P.; PACHECO, J. A.; SALES, S. (Orgs.). Currículo, conhecimento e avaliação: divergências e tensões. Curitiba: CRV, 2013. p. 155-175.

VELASCO, D. B. "Realidade do aluno", “cidadão crítico", "conhecimento escolar": que articulações possíveis no currículo de História? 2013. 180 f. Dissertação (Mestrado em Educação) - Universidade Federal do Rio de Janeiro, Rio de Janeiro, RJ, 2013.

Recebido em 31/10/2015

Versão corrigida recebida em 02/05/2016

Aceito em 06/06/2016

Práxis Educativa, Ponta Grossa, p. 693-713, v. 11, n. 3, set./dez. 2016 Disponível em: <http://www.revistas2.uepg.br/index.php/praxiseducativa> 